\title{
Evidence of autonomic dysreflexia during functional electrical stimulation in individuals with spinal cord injuries
}

\author{
E A Ashley, ${ }^{1} \mathrm{~J} \mathrm{~J}$ Laskin BSc, ${ }^{2} \mathrm{~L}$ M Olenik MSc ${ }^{2}$ R Burnham MD FRCPC, ${ }^{2}$ \\ R D Steadward $\mathrm{PhD},{ }^{2}$ D C Cumming MBChB FROCG FRCSC, ${ }^{3}$ G D Wheeler $\mathrm{PhD}^{2 *}$ \\ ${ }^{1}$ Institute of Physiology, University of Glasgow, Scotland; ${ }^{2}$ The Rick Hansen Centre, \\ W1-67 Van Vliet Centre, University of Alberta, Edmonton, T6G 2H9, Canada; \\ ${ }^{3}$ Department of Obstetrics and Gynaecology, Walter Mackenzie Health Sciences Centre, \\ University of Alberta, Canada.
}

The purpose of the investigation was to examine the safety and efficacy of functional electrical stimulation (FES)-assisted hydraulic resistance training in improving cardiovascular fitness in persons with spinal cord injuries. The cardiopulmonary responses of 10 high spinal cord injured (SCI) and five able bodied (AB) subjects were assessed during three bouts of FES-assisted leg extension exercise. The protocol involved three 30-minute tests: (1) unloaded leg extension, (2) hydraulically-resisted leg extension (loaded), and (3) a reproduction of the unloaded and loaded protocols to measure cardiac output (Q). Pre-measurements were made of body mass, mean limb weight, maximal force output and maximal oxygen uptake (incremental arm ergometry). Oxygen uptake (VO2), minute ventilation (Ve), respiratory exchange ratio (RER), heart rate $(\mathrm{HR})$, blood pressure (BP) were recorded before, during and after tests. There was a significant difference in VO2 max between SCI and AB subjects. Cardiac output significantly increased between the loaded and unloaded tests. The significant increases from rest to unloaded and loaded exercise pointed to the potential value of adding resistance to a leg extension training regime. Heart rate and $\mathrm{BP}$ of the participants with SCI consistently demonstrated a response suggestive of autonomic dysreflexia. Upon stimulation an immediate increase in (predominantly systolic) BP was observed, followed by a fall in HR. On cessation of stimulation HR exhibited a substantial rebound effect and BP returned to normal levels. This response was highly reproducible and suggests caution be exercised in the use of FES for people with SCI with lesion levels above the major splanchnic outflow (T6).

Keywords: spinal cord injury; functional electrical stimulation; autonomic dysreflexia; resistance training; cardiovascular.

\section{Introduction}

The use of electrical stimulation in the rehabilitation of people with spinal cord injuries has a long and varied history. ${ }^{1}$ In the past, mechanisms such as axonal regeneration and spinal cord grafting have been investigated. ${ }^{2}$ The present approach is to use electrical current to artificially stimulate the paralysed musculature: a technique known as functional electrical stimulation (FES). Recently the technique has been

\footnotetext{
${ }^{*}$ Correspondence.
}

widely used to produce movements for grasping, ${ }^{3}$ standing, ${ }^{4}$ walking, ${ }^{5}$ and increasingly, physical training. ${ }^{6}$

Several investigations, ${ }^{7-10}$ have documented improvements in cardiopulmonary fitness from FES-induced or assisted exercise. This is particularly relevant since cardiovascular disease now represents the number one cause of mortality in the spinal cord injured, having replaced renal complications. ${ }^{11}$ In addition, it has been found that the normal daily activities of people with spinal cord injuries are insufficient to maintain cardiovascular fitness. ${ }^{12}$ 
Other benefits of FES-assisted exercise include increased bone mass ${ }^{6}$ reduction in decubitus uclers, ${ }^{13}$ and reduced spasticity (anecdotal). Also important are the psychological benefits associated with exercise in general. ${ }^{14}$ Little attention has been paid to questions of safety, although incidents of autonomic dysreflexia, ${ }^{15}$ exercise-induced hypertension, ${ }^{8}$ and consequences of thermoregulatory deficiency ${ }^{15}$ have been reported anecdotally by investigators but apparently dismissed as infrequent and relatively unimportant.

Thus, the purpose of our study was to test the efficacy and safety of the 'Hydrastim' FES-assisted hydraulic leg training device developed in the Rick Hansen Centre (Biomech Industries, Ltd, Edmonton, Alberta, Canada).

\section{Subjects and methods}

Eleven individuals with high spinal cord

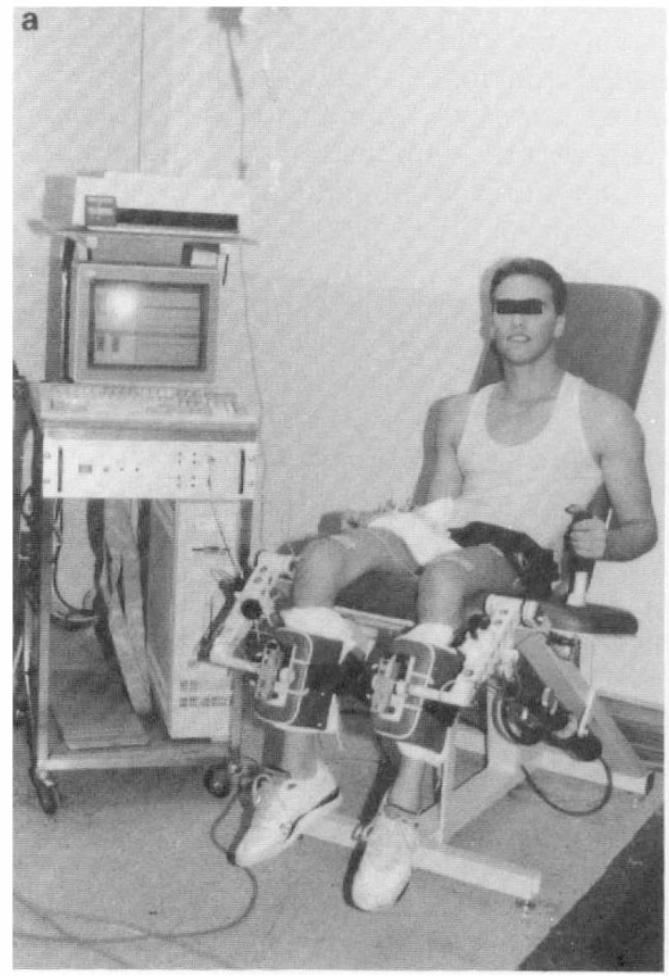

injuries (seven quadriplegic and four paraplegic, lesion levels $\mathrm{C} 3 / 4-\mathrm{T} 4 / 5$ ) and five able bodied (AB) controls volunteered to take part in the investigation. One subject was eliminated from the subject pool because he was taking beta blockers. All subjects gave informed consent to participate in this study which was approved by an institutional ethical review body. All SCI subjects had undergone some previous FES training, and were in good health. All underwent a bone scan (radio nucleotide method) and bone density measurement (dual energy xray absorptiometry, Hologic Inc, Waltham, MA) to eliminate the possibility of existing stress fractures in the femur and tibia.

On the first visit, subjects were weighed, then transferred to the Hydrastin device (Figs 1 and 2). This consists of a modified hydragym (Hydragym, Canada, Ltd) hydraulic resistance leg extension and flexion device interfaced with an IBM computer

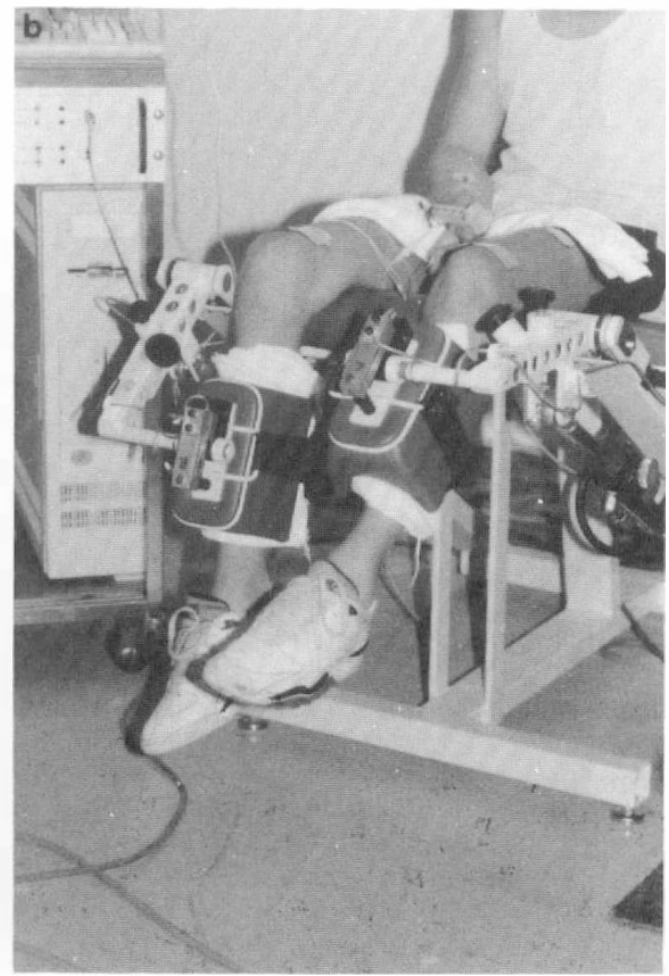

Figure 1 (a) The Hydrastim apparatus. (b) The Hydrastim apparatus-modified leg pads and lever arms with force transducers and electronic goniometers. 


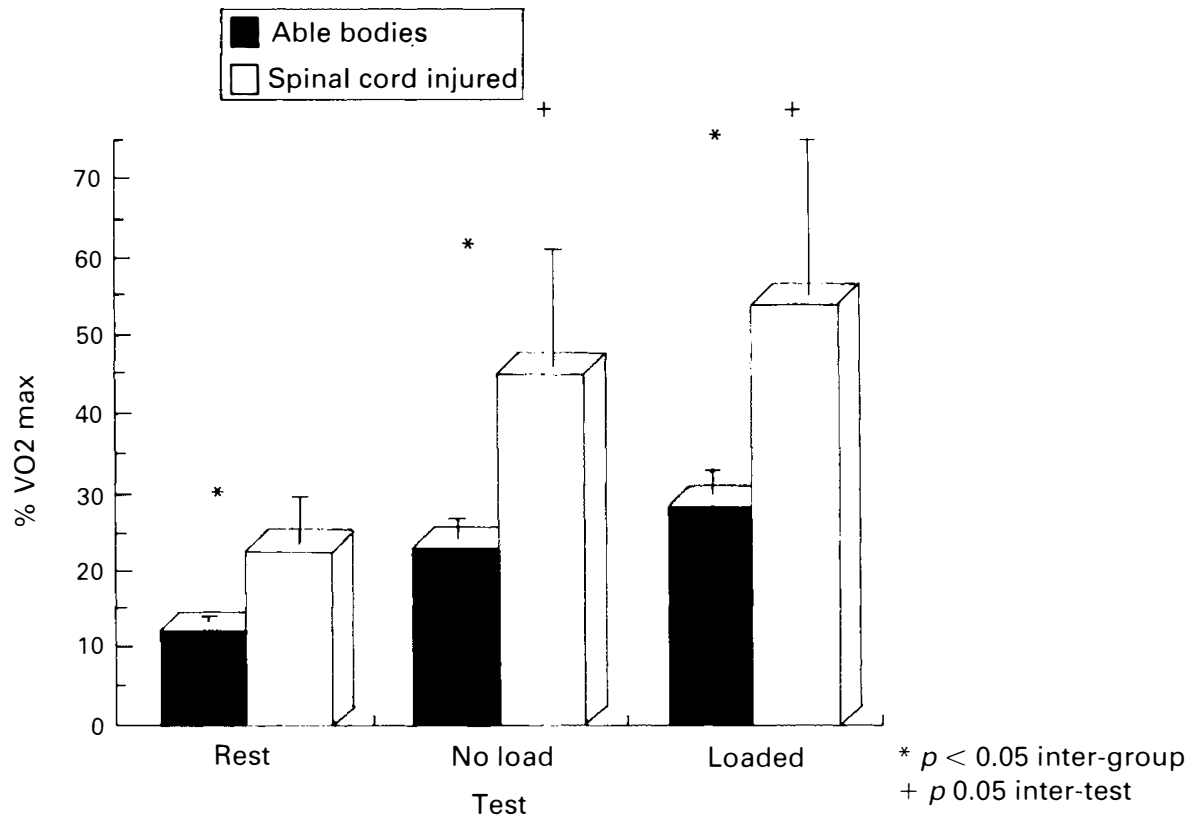

Figure 2 Resting and peak mean oxygen consumption levels expressed as percent change.

(model PS2 80). Modifications included electronic level arm goniometers and force transducers mounted on extended level arm leg pads. Leg pads were lengthened and increased in width to maximize force dissipation across the anterior portion of the tibia. The computer system delivered muscle stimulation via a computer controlled four channel neuromuscular stimulation device ('Quadstim'-Biomech Industries, Edmonton, Ltd) connected to the subject via commercially available reusable surface electrodes (Chattangooga Corp, TN). Stimulation parameters included square monophasic waves, $250 \mathrm{~ms}$ pulse width, $50 \mathrm{~Hz}, 0-160 \mathrm{~mA}$ and a $50 \%$ duty cycle (set at 4 seconds on/off time). The device is also designed to measure force output on a continual periodic basis during exercise periods.

Subjects rested for 10 minutes or until a steady state baseline oxygen consumption value was achieved. Electrodes were placed over the motor points and musculotendinous junctions of the quadriceps muscle groups of each leg. Initial stimulation intensity was set at a level sufficient to achieve full leg extension, and the intensity was periodically adjusted to maintain the extensions. Stimulation continued for 20 mintues of exercise (without resistance), followed by a recovery period to return to resting values ('no load' test).

On the second visit, the above protocol was repeated with resistance ('load' test). Resistance was added to leg movement by attaching the subject's legs to the padded lever arms at the lowest resistance setting on the Hydrastim device. Measurements of leg weight and maximum force output during the exercise period were taken to quantify the force output on the unloaded extension.

On all occasions, metabolic variables were measured by expired air analysis. Oxygen consumption (VO2), minute ventilation (Ve), tidal volume (TV), tidal frequency (f), and respiratory exchange ratio (RER) were obtained via a metabolic cart (MMC Horizon, SensorMedics CA). Measurements were taken every 15 seconds and then averaged for 1 minute periods over 30 minutes including 5 minutes of rest and 5 minutes of recovery. Heart rate (HR) was monitored continuously by a PE sport-tester 
(Model 3000) with values recorded every minute. Blood pressure - systolic (SBP) and diastolic (DBP) - was measured by auscultation: at rest, after 1 minute of exercise and every 5 minutes thereafter; and after 1 minute and 5 minutes of recovery.

On the third visit, subjects repeated the above protocols in succession for measurements of cardiac output (Q) by a noninvasive, $\mathrm{CO}_{2}$ rebreathing method. ${ }^{16}$ Cardiac output was assessed independently because the rapid ventilation required for this method would have had a significant effect on the original test results. The procedure was conducted at equivalent VO2 values and at a stimulation intensity equal to the original test.

To assess the percentage maximum effort required for FES-assisted leg training, maximum oxygen consumption ( $\mathrm{VO} 2 \mathrm{max}$ ) was determined on the fourth visit by an incremental arm ergometry method. Arm crank rate was maintained at $50 \mathrm{rpm}$ and power output was increased by $10 \mathrm{~W}$ every 2 minutes thereafter. The test was deemed over if the arm crank rate fell below $50 \mathrm{rpm}$ or if the subject reached exhaustion.

\section{Data analysis}

In addition to the measured variables, values for mean arterial pressure (MAP = diastolic $+\frac{1}{3}$ pulse pressure) were computed. Values for $\mathrm{VO} 2$ were expressed in absolute terms $\left(1 / \mathrm{min}^{-1}\right)$, relative to body weight $\left(\mathrm{ml} / \mathrm{kg} / \mathrm{min}^{-1}\right)$ and relative to maximum oxygen uptake at \% VO2 max.

Preliminary analysis showed no differences between quadriplegics and paraplegics, therefore the data were pooled into one SCI group.

A one way analysis of variance $(A B$ vs SCI) with repeated measures (rest vs no load vs load) was performed on the data and independent $t$-tests were performed on the static values (body mass, VO2 max, limb weight and maximal force output). Limb weight showed no significant difference between the groups and was not included as a covariable in the ANOVA.

Statistical significance was set at $p<0.05$.

\section{Results}

Subject details are reported in Table I. Resting and steady-state values of metabolic parameters, heart rate and blood pressure for both tests and both populations are reported in Tables II and III.

As expected absolute and relative $\mathrm{VO}_{2}$ max levels were significantly greater for the AB group than for the SCI group $(p=0.01)$.

Absolute, relative, and percentage $\mathrm{VO} 2$ max values increased significantly from rest to no load to load in both groups. Only percentage $\mathrm{VO}_{2}$ max values were different between the groups. Percentage maximum effort for SCI subjects was significantly higher than $\mathrm{AB}$ subjects during all three conditions and was also significantly increased from rest to no load to load (Fig 2). In addition, $\mathrm{Ve}$ increased significantly from rest to no load to load.

In comparison, RER increased significantly only from rest to no load and from rest to load and not between no load and load.

Surprisingly, values for $Q$ showed no significant increase from rest to no load but were significantly higher from no load to load. This was seen in AB subjects as well as SCI.

However, it was the HR and BP profiles

Table I Subject information

\begin{tabular}{ccccc}
\hline Subject & Age & Gender & $\begin{array}{c}\text { Level of } \\
\text { injury }\end{array}$ & $\begin{array}{c}\text { Time since } \\
\text { injury (yrs) }\end{array}$ \\
\hline 1 & 22 & M & \multicolumn{2}{c}{ Able bodied control } \\
2 & 22 & F & \multicolumn{2}{c}{ Able bodied control } \\
Able bodied control \\
3 & 21 & M & \multicolumn{2}{c}{ Able bodied control } \\
4 & 21 & F & \multicolumn{2}{c}{ Able bodied control } \\
5 & 18 & M & Able bo & 7 \\
6 & 25 & M & C6-7 & 2.5 \\
7 & 41 & M & C4-5 & 2 \\
8 & 29 & M & C6-7 & 10 \\
9 & 25 & M & T3-4 & 10 \\
10 & 37 & M & T5-6 & 20 \\
11 & 25 & M & T4 & 7 \\
12 & 36 & F & C6-7 & 19 \\
13 & 29 & M & C7-T1 & 2 \\
14 & 40 & M & C5-6 & 5 \\
15 & 28 & M & C6 & 4 \\
16 & 38 & M & C5 & 5 \\
\hline
\end{tabular}

aincomplete. 
Table II Mean resting and peak no load and load data

\begin{tabular}{|c|c|c|c|c|c|c|}
\hline & \multicolumn{2}{|c|}{ Rest } & \multicolumn{2}{|c|}{ No load } & \multicolumn{2}{|c|}{ Load } \\
\hline & Mean & SD & Mean & SD & Mean & SD \\
\hline \multicolumn{7}{|c|}{$\mathrm{VO}_{2} \mathrm{a}(\mathrm{l} / \mathrm{min})$} \\
\hline $\mathrm{AB}$ & 0.217 & 0.034 & $0.417^{\mathrm{a}}$ & 0.093 & $0.514^{b, c}$ & 0.075 \\
\hline SCI & 0.232 & 0.041 & $0.44^{\mathrm{a}}$ & 0.085 & $0.52^{\mathrm{b}, \mathrm{c}}$ & 0.134 \\
\hline \multicolumn{7}{|c|}{$\mathrm{VO}_{2} \mathrm{~b}(\mathrm{ml} / \mathrm{kg} / \mathrm{min})$} \\
\hline $\mathrm{AB}$ & 3.34 & 0.54 & $6.33^{\mathrm{a}}$ & 0.81 & $7.85^{\mathrm{b}, \mathrm{c}}$ & 0.71 \\
\hline SCI & 3.38 & 0.63 & $6.45^{\mathrm{a}}$ & 1.38 & $7.65^{\mathrm{b}, \mathrm{c}}$ & 1.95 \\
\hline \multicolumn{7}{|c|}{$\mathrm{VO}_{2} \mathrm{c}(\% \max )$} \\
\hline $\mathrm{AB}$ & 11.9 & 0.9 & $22.7^{\mathrm{a}}$ & 2.5 & $28.2^{\mathrm{b}, \mathrm{c}}$ & 3.0 \\
\hline SCI & 21.3 & $6.2^{\mathrm{d}}$ & $41.5^{\mathrm{a}}$ & $16.6^{\mathrm{d}}$ & $49.5^{\mathrm{b}, \mathrm{c}}$ & 21.9 \\
\hline \multicolumn{7}{|c|}{$\mathrm{f}(\mathrm{br} / \mathrm{min})$} \\
\hline $\mathrm{AB}$ & 10 & 2 & $23^{\mathrm{a}}$ & 4 & $22.4^{\mathrm{c}}$ & 5 \\
\hline SCI & 13 & 3 & $21.5^{\mathrm{a}}$ & 5 & $23.3^{\mathrm{c}}$ & 6 \\
\hline \multicolumn{7}{|c|}{ TV (1/br) } \\
\hline $\mathrm{AB}$ & 0.587 & 0.152 & $0.852^{\mathrm{a}}$ & 0.184 & $0.99^{c}$ & 0.272 \\
\hline SCI & 0.504 & 0.103 & $0.938^{\mathrm{a}}$ & 0.262 & $1.006^{\mathrm{c}}$ & 0.215 \\
\hline \multicolumn{7}{|c|}{$\mathrm{V}_{\mathrm{e}}(\mathrm{l} / \mathrm{min})$} \\
\hline $\mathrm{AB}$ & 7.6 & 1.7 & $13.7^{\mathrm{a}}$ & 1.2 & $17.3^{\mathrm{b}, \mathrm{c}}$ & 4.1 \\
\hline $\mathrm{SCI}$ & 7.9 & 1.3 & $16.5^{\mathrm{a}}$ & 3.8 & $21.0^{\mathrm{b}, \mathrm{c}}$ & 7.3 \\
\hline \multicolumn{7}{|l|}{ RER } \\
\hline AB & 0.77 & 0.05 & $0.9^{\mathrm{a}}$ & 0.04 & $0.99^{\mathrm{c}}$ & 0.14 \\
\hline $\mathrm{SCI}$ & 0.68 & 0.06 & $0.96^{\mathrm{a}}$ & 0.08 & $1.03^{\mathrm{c}}$ & 0.11 \\
\hline \multicolumn{7}{|c|}{ HR (bpm) } \\
\hline $\mathrm{AB}$ & 59 & 4 & $79.6^{\mathrm{a}}$ & 5 & $87.8^{\mathrm{c}}$ & 6 \\
\hline SCI & 73 & 14 & $88.4^{\mathrm{a}}$ & 20 & $93^{c}$ & 22 \\
\hline \multicolumn{7}{|c|}{$\mathrm{SBP}(\mathrm{mmHg})$} \\
\hline $\mathrm{AB}$ & 107 & 12 & 128 & 14 & 131 & 8 \\
\hline SCI & 91 & 18 & $139^{\mathrm{a}}$ & 21 & $164.2^{\mathrm{c}}$ & 26 \\
\hline \multicolumn{7}{|c|}{ DBP $(\mathrm{mmHg})$} \\
\hline $\mathrm{AB}$ & 73 & 6 & 90 & 14 & 90 & 7 \\
\hline SCI & 61 & 12 & $87.2^{\mathrm{a}}$ & 17 & $96.8^{c}$ & 14 \\
\hline \multicolumn{7}{|c|}{ MAP $(\mathrm{mmHg})$} \\
\hline $\mathrm{AB}$ & 84.9 & 6.9 & 102.7 & 13.8 & $102.3^{c}$ & 5.9 \\
\hline SCI & 71.9 & 11.9 & $104.4^{\mathrm{a}}$ & 16.1 & $118.3^{c}$ & 15.5 \\
\hline \multicolumn{7}{|c|}{$\mathrm{Q}(\mathrm{l} / \mathrm{min})$} \\
\hline $\mathrm{AB}$ & 5.6 & 1.9 & 7.3 & 1.1 & $9.702^{b, c}$ & 1.6 \\
\hline SCI & 4.8 & 1.3 & 6.7 & 2.3 & $9.9^{b, c}$ & 3.6 \\
\hline
\end{tabular}

${ }^{\mathrm{d}}$ main effect for group $(p<0.05)$.

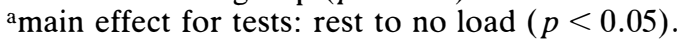

bmain effect for tests: no load to load $(p<0.05)$.

${ }^{c}$ main effect for tests: rest to load $(p<0.05)$.

$\mathrm{f}=$ frequency of ventilation; $\mathrm{TV}=$ tidal volume; $\mathrm{HR}=$ heart rate; $\mathrm{SBP}=$ systolic blood pressure; $\mathrm{DBP}=$ diastolic blood pressure; MAP $=$ mean arterial pressure; $\mathrm{Q}=$ cardiac output .

which demonstrated the most interesting results. These were unexpected but highly reproducible. The mean response for the loaded condition in both $\mathrm{SCI}$ and $\mathrm{AB}$ groups is outlined below and in Figures 3 and 4. Profiles of no load and loaded conditions were not significantly different although the effect was greater under loaded conditions.

Immediately after turning on the stimula- 
Table III Baseline variables for SCI and $\mathrm{AB}$

\begin{tabular}{lclc}
\hline Test & $\begin{array}{c}\text { Subject } \\
\text { group }\end{array}$ & Mean SD \\
\hline
\end{tabular}

Body mass (kg)

$\begin{array}{llr}\text { AB } & 65.48 & 7.71 \\ \text { SCI } & 71.33 & 22.08\end{array}$

$\mathrm{VO}_{2} \max (\mathrm{ml} / \mathrm{kg} / \mathrm{min})$

$\begin{array}{lll}\text { AB } & 28.16^{\mathrm{a}} & 4.29 \\ \mathrm{SCI} & 17.41 & 6.39\end{array}$

Limb weight $(\mathrm{N})$

$\begin{array}{lrr}\text { AB } & 55.82 & 11.83 \\ \text { SCI } & 50.81 & 9.36\end{array}$

Mean maximum force

$\begin{array}{llll}\text { stimulated } & \text { AB } & 72.76 & 24.12 \\ & \text { SCI } & 77.01 & 33.69\end{array}$

Voluntary

$\begin{array}{lcc}\mathrm{AB} & 165.53^{\mathrm{b}} & 35.16 \\ \mathrm{SCI} & - & -\end{array}$

${ }^{\text {a }} p<0.01$.

${ }^{\mathrm{b}} p<0.001$.

tion in the spinal cord injured group, a marked drop in HR and a concomitant rise in BP (predominantly systolic) was observed. During the course of the test, HR would typically rise to just above the resting level and BP would continue to rise in some subjects and level off or fall in others. In two of the subjects a SBP of over $200 \mathrm{mmHg}$ was recorded and stimulation was immediately turned down resulting in an immediate reduction in SBP to below $200 \mathrm{mmHg}$. On completion of the exercise period and cessation of stimulation, a rebound increase in HR was observed to a value generally above the exercise maximum. Concurrently, BP would fall rapidly to baseline levels or lower. This response was observed in eight of 10 subjects.

Peak HRs were not different between groups but were significantly increased from rest to no load to load. Notably, mean peak values for SBP, DBP and MAP were significantly different from rest to no load to load in the $\mathrm{SCI}$ group but not for the $\mathrm{AB}$ group (Fig 5).

\section{Discussion}

The focus of this study was to test the efficacy and safety of FES as an aid in cardiopulmonary exercise in people with spinal cord injuries.

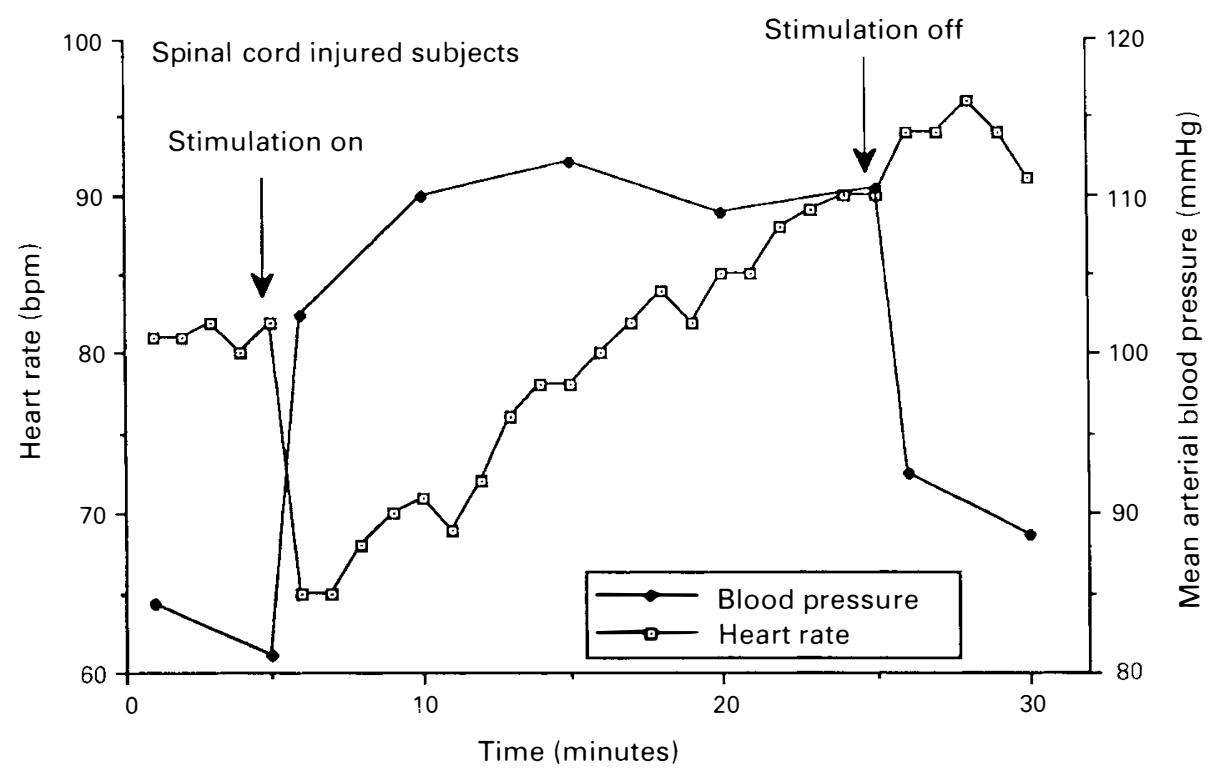

Figure 3 Mean heart rate and mean arterial blood pressure levels for spinal cord injured under loaded conditions. 


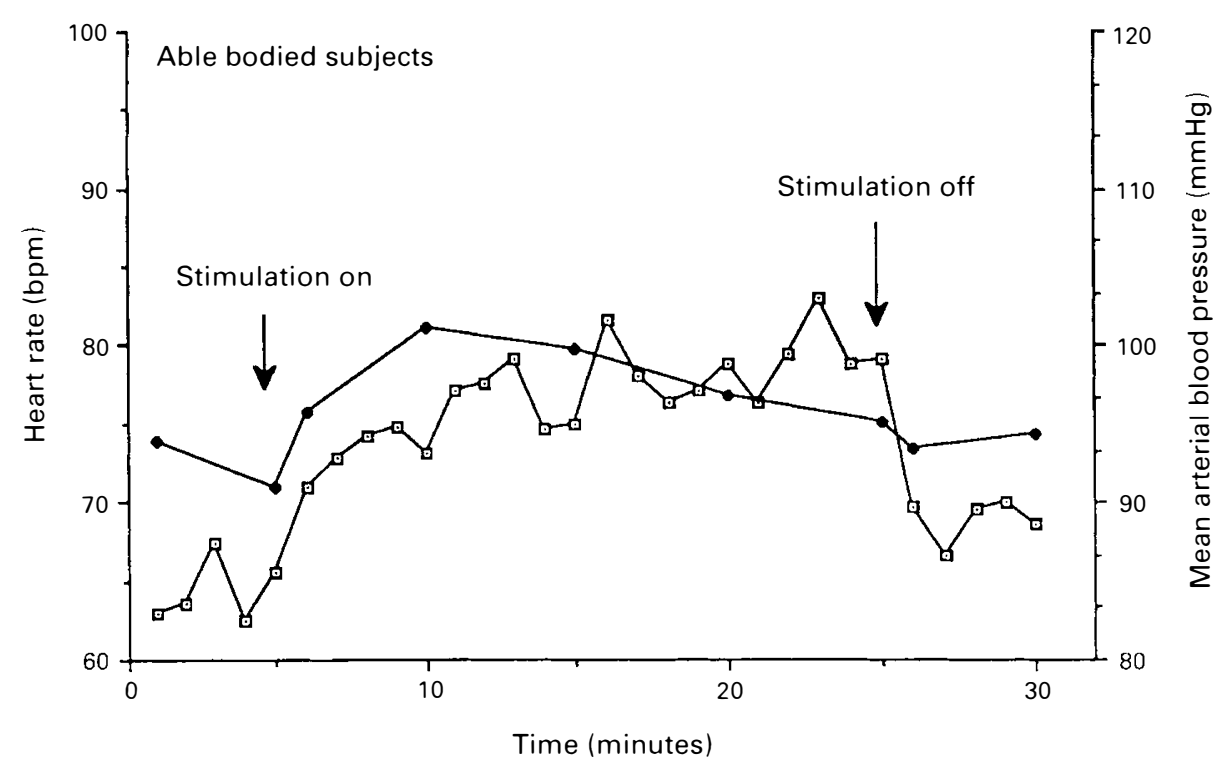

Figure 4 Mean heart rate and mean arterial blood pressure levels for the able bodied subjects under loaded conditions.

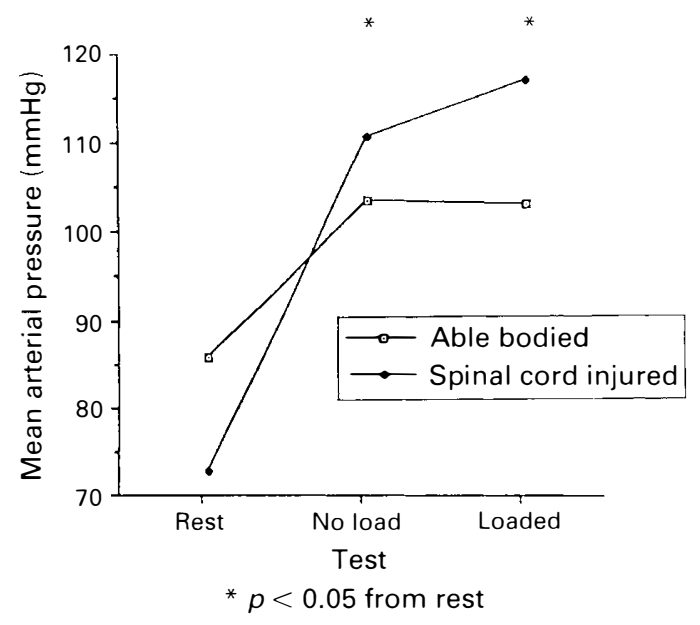

Figure 5 Change in mean arterial pressure (MAP) from rest to no load to load for SCI and $\mathrm{AB}$.

\section{Efficacy}

The significant increase in oxygen consumption of the load over the no load condition suggests that it is worthwhile to include resistance in FES training programs. Since the loaded test incurred a mean peak VO2 of almost $50 \%$ of the maximum aerobic power of the SCI group, leg extension with resistance may represent a suitable aerobic training program for maintenance of cardiovascular system (CVS) fitness (especially given that current American College of Sports Medicine guidelines ${ }^{17}$ suggest effective CVS conditioning at $40-85 \%$ of $\mathrm{VO}_{2}$ max for 15-60 minutes three to five times per week.)

The Hydrastim system presents several advantages for the SCI population over the use of free weights and other resistance training devices by providing increased control of leg movement and variable accommodating resistance. We suggest that these features would allow its use at a very early stage in the rehabilitation process and thereafter as part of a regular exercise training program.

The changes in cardiac output (Q) provide further evidence for the use of the Hydrastim system as a training tool. Leg extension exercise may be expected to increase venous return through the skeletal muscle venous pump mechanism. ${ }^{18}$ This, in turn, should increase the contractility of the heart, stroke volume and ultimately the $\mathrm{Q}$ (Frank-Starling relationship). While impor- 
tant for the $\mathrm{AB}$ subjects, an increase in $\mathrm{Q}$ is of greater importance for the SCI population in alleviating lower limb venous pooling secondary to circulatory hypokinesis. The fact that there was no significant difference demonstrated between the resting value for $Q$ and the no load value, suggests that simple leg extension alone is not a sufficient stimulus to induce increases in venous return. In comparison, the loaded test produced significantly higher values suggesting that the addition of hydraulic resistance to a simple FES leg extension program is a worthwhile option for cardiac training. Increases in Ve between tests were not surprising because of the close relationship between $\mathrm{Ve}$ and $\mathrm{VO}_{2}{ }^{16}$ and considering that studies indicate that the effects of respiratory muscle paralysis ${ }^{19}$ do not act as a limiting factor during exercise in the SCI population. ${ }^{20,21,22}$

In contrast, RER values increased between test conditions but not between groups. This was unexpected for a variety of reasons: (1) the change in fiber type of paralyzed muscle ${ }^{23}$ the synchronized nature of the motor unit stimulation, the fact that FES tends to recruit large superficial motor neurons more efficiently than deeper, smaller motor neurons, ${ }^{24}$ and the 'reverse size principle' nature of the motor unit excitation $^{1}$ should result in substrate use closer to the glycolytic end of the spectrum than the oxidative end; (2) a lower VO2 max would inhibit fat usage and promote carbohydrate usage for a given workload; ${ }^{16}$ and (3) paralyzed muscle has been shown to elicit greater lactate accumulation during FES than nonparalyzed muscle. ${ }^{25}$ (Accumulation of lactate inhibits free fatty acid (FFA) release and would tend to promote carbohydrate usage. ${ }^{16}$ ) All of the above would seem to favour elevation of RER for a given workload from the AB group to the SCI group and although a rise was noted, it only approached significance. An explanation for this may be found in the ensuing discussion regarding autonomic dysreflexia which is associated with greatly elevated levels of noradrenaline (NA). ${ }^{26}$ This increase in NA would tend to stimulate FFA mobilization and usage which, in turn, would suppress the RER. ${ }^{16}$
Safety

Autonomic dysreflexia is a syndrome of unchecked reflex sympathetic discharge unique to SCI individuals with lesions above the major splanchnic outflow (around T6). ${ }^{27}$ It typically occurs in response to a nociceptive stimulus below the level of the lesion. The classically described symptoms are bradycardia secondary to hypertension, anxiety, sweating and headache. ${ }^{26}$ It is associated with large increases in circulating noradrenaline levels with little change in circulating adrenaline. ${ }^{26}$ It has the potential to induce, through associated increases in $\mathrm{BP}$, a number of hazardous conditions including cerebral haemorrhage and cardiac arrhythmia. ${ }^{28}$ Recent reports ${ }^{29.30}$ have also documented its intentional induction by elite wheelchair athletes for performance enhancement. However, very little has been written of it in connection with FES.

The highly consistent nature of the CVS response in this study is strongly suggestive of autonomic dysreflexia. Furthermore, it is not surprising that the effect was observed in both paraplegic and quadriplegic subjects since all our subjects had lesions above the T6 level.

The postulated mechanism is as follows (Fig 6).

Electrical stimulation is turned on and immediately perceived as a noxious stimulus by intact pain receptors in the paralyzed limbs. These relay via $\mathrm{C}$ pain fibers to the spinal cord causing massive sympathetic discharge below the level of the lesion resulting in peripheral vasoconstriction. In turn, this causes hypertension (observed), piloerection and gooseflesh (observed). In response to this sudden hypertension, the aortic arch and carotid sinus baroreceptors relay messages, via the vagus and glossopharyngeal nerves, to the tractus solitarius and on to the vasomotor area in the ventrolateral medulla. Subsequent activity there results in a two-fold response: (1) the vagal centre is excited producing bradycardia (observed). (However, since pressure in a tube, although affected to the 4 th power of the radius is only linearly affected by the flow rate, bradycardia is of little use in counterbalancing the hypertension induced by vasoconstriction. ${ }^{27}$ ); and (2) descending inhibit- 


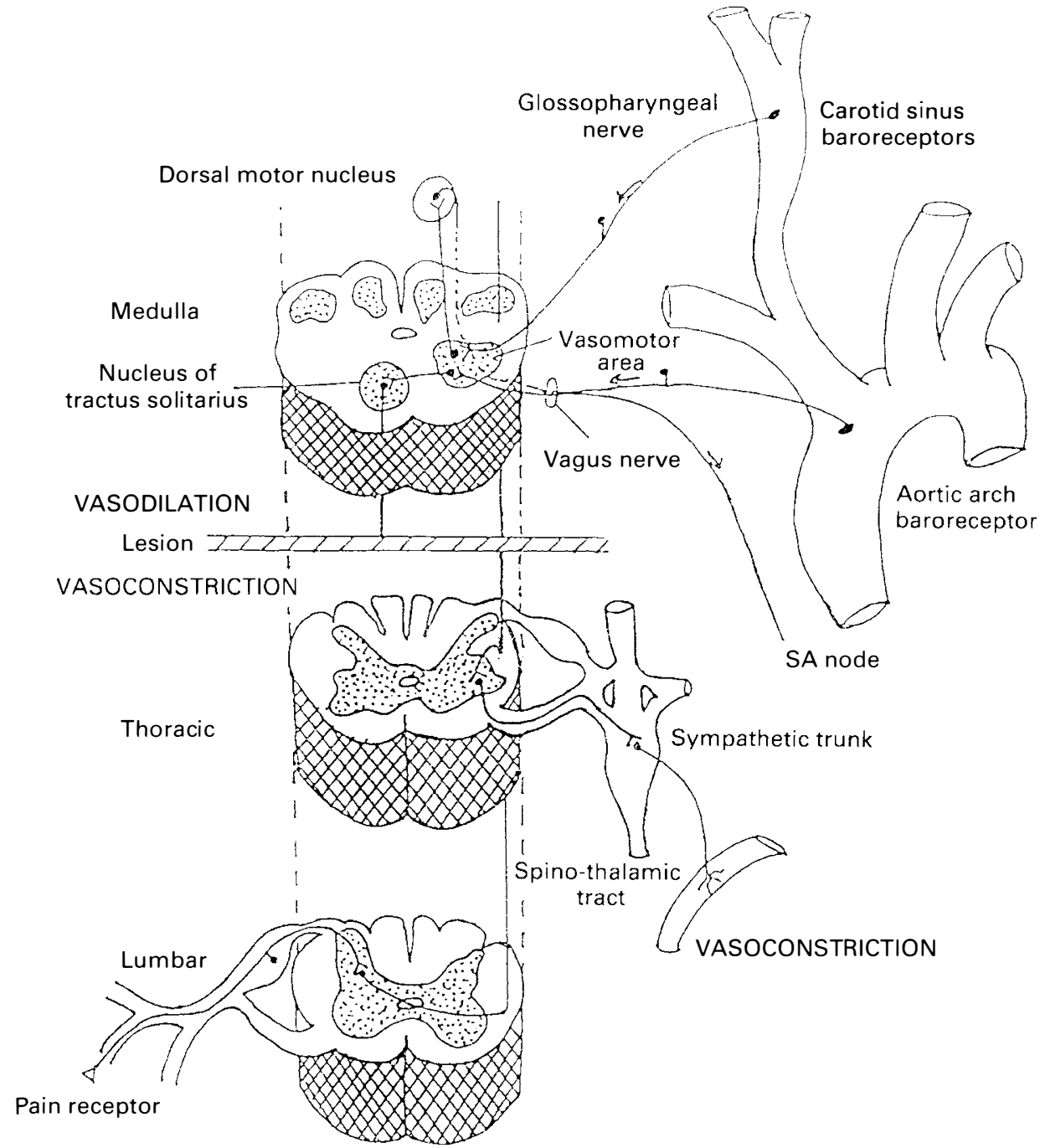

Figure 6 Mechanism of autonomic dysreflexia.

ory fibers with vasodilatory activity are excited. These fibers, however, are unable to traverse the spinal lesion and while a reflex vasodilation occurs above the lesion, no homeostatic effect occurs below. ${ }^{18}$ Thus a compensatory drop in blood pressure cannot occur and hypertension persists, or is increased, as stimulation is increased to maintain leg extension (observed).

On cessation of stimulation, the above effects are reversed as the nociceptive stimulus and associated sympathetic outflow is withdrawn resulting in decreased $\mathrm{BP}$ and a rebound compensatory increase in HR (observed).

We interpret these observations as strong evidence for autonomic dysreflexia induced by the electrical stimulation. In addition, anecdotal reports of headache following test procedures support this hypothesis. The possibility that we may have witnessed a direct electrical effect of the stimulation on the heart (or recording equipment) was considered. However, as no similar effect was observed in the $\mathrm{AB}$ group and transient increases in HR were observed on turning 
up the stimulation in both groups (consistent with Moltner's ${ }^{31}$ hypothesized 'nocifensive reflex'), it was concluded that this truly was a physiological response to a painful stimulus. (The AB subjects confirmed that the stimulation was indeed painful.)

Two questions immediately arise. First, why has this not (to our knowledge) been documented as a common occurrence before; and second, what are the implications?

Several authors have documented stimulation related increases in BP. Mathias et $a l^{32}$ showed significant increases in BP and NA upon electrical stimulation of muscles; however, no stimulus parameters are detailed in the paper so it is difficult to make a comparison. Arnold et $a l^{33}$ noted at least one case of an elevated BP (which was then pharmacologically suppressed) on their initial round of FES. In addition, there have been a number of reports ${ }^{34,35}$ detailing decreased HRs for FES-assisted exercise when compared with voluntary exercise at similar levels of VO2. The traditional explanation for this HR response has been the well documented effect (in the AB population $^{36}$ ) that lower limb exercise produces a smaller cardiovascular response than upper limb exercise at the same VO2. However, in light of the atrophied state of the lower limb musculature of individuals with SCI it is the impression of these researchers that autonomic dysreflexia represents a more likely explanation for the reported decreases in HR. Dysreflexia in response to FES has not been entirely ignored by investigators; in fact several accounts state specifically that no instances of autonomic dysreflexia were observed. ${ }^{9,37,38}$

It has been established for some time that: (1) the sensation of pain primarily depends upon the charge of a single, given pulse; (2) constant voltage is preferable to constant current; and (3) a short pulse width of around $0.3 \mathrm{~ms}$ is more comfortable than a longer one. ${ }^{39}$ In addition, recent research has focused on altering the shape of the wave, ${ }^{13,40}$ examples being triangular, sine, square, and trapezoidal. However, a comparison of this study with several others (Table IV) reveals little difference between stimulation parameters.

Another factor worthy of consideration is the electrodes and their placement. The effects of different types and sizes of electrodes, in terms of preferentially stimulating alpha-motor neurons, are largely unresearched as are the effects of placement. (It is recommended to position the electrodes over the motor points of the muscle..$^{9.42}$ ) Thus, we find it hard to determine the specific nature of the nociceptive stimulus. At this point, we are unable to discriminate to what extent the pain causing the dysreflexic response should be attributed to surface pain receptors or to painful muscle contractions. Preliminary results of a study in progress at the Rick Hansen Centre (University of Alberta), suggest that the application of a surface anaesthetic prior to FES has some effect on the pain perceived by able bodied subjects. ${ }^{43}$ We plan to extend this study to investigate the effects of the anaesthetic with FES when applied to

Table IV Comparison of functional electrical stimulation parameters among this and previous investigations

\begin{tabular}{|c|c|c|c|c|c|}
\hline \multirow[t]{2}{*}{ System } & \multicolumn{5}{|c|}{ Parameters } \\
\hline & Current & $\mathrm{f}$ & Pulse width & Shape and form & Investigators \\
\hline REGYS I & $0-130 \mathrm{~mA}$ & $30 \mathrm{~Hz}$ & $400 \mathrm{~s}$ & Rectangular monophasic & Ragnarsson et al $(1988)^{8}$ \\
\hline \multirow[t]{3}{*}{ ERGYS I } & $0-130 \mathrm{~mA}$ & $35 \mathrm{~Hz}$ & $375 \mathrm{~s}$ & Rectangular monophasic & Hooker et al $(1990)^{9}$ \\
\hline & $0-150 \mathrm{~mA}$ & $30 \mathrm{~Hz}$ & $200 \mathrm{~s}$ & & Gruner et al $(1983)^{40}$ \\
\hline & $0-130 \mathrm{~mA}$ & $40 \mathrm{~Hz}$ & $375 \mathrm{~s}$ & Rectangular monophasic & Nash et al $(1991)^{10}$ \\
\hline \multicolumn{4}{|c|}{ Respond (Medtronics Inc) } & Square biphasic & Petrofsky $(1992)^{13}$ \\
\hline \multicolumn{6}{|c|}{ 'Quadstim' (Biomech Inc) } \\
\hline & $0-160 \mathrm{~mA}$ & $50 \mathrm{~Hz}$ & $250 \mathrm{~s}$ & Square monophasic & (this study) \\
\hline
\end{tabular}

$\mathrm{f}=$ frequency of stimulation. 
people with spinal cord injuries. It has been suggested that there is a distinction between the pain from a physical stimulus and the discomfort from muscle contraction. ${ }^{44}$ However, at this point in time we are uncertain whether or not this finding applies to the dysreflexic response seen in people with spinal cord injuries. Furthermore, since there is an immediate $\mathrm{HR}$ and $\mathrm{BP}$ reaction it seems that, at least initially, the dysreflexia is in response to the pain associated with the electrical stimulus. Nonetheless, most studies in this field tend to report HR and BP measurements either pre and post testing or, at most, every 5 minutes during. In light of this most recent evidence, it would seem advisable to take HR measurements continuously and BP measurements as often as is logistically possible.

Two of our subjects did not exhibit this response. One had an incomplete lesion (sensory spared), and as a result the stimulus level which could be tolerated was not as high as the other SCI subjects. The second was the only subject in possession of his own stimulator (training up to 60 minutes, three times per week). It is possible that this subject had acquired some form of pain habituation. Therefore, some other questions which need to be addressed are whether the benefits accrued from FES outweigh not only the risk inherent in reaching a stage of pain habituation, but also the longterm repercussions of training in a hypertensive state.

Accepting at least the possibility that FES-induced autonomic dysreflexia is occurring, perhaps undetected, in persons taking part in FES programs, we suggest a thorough investigation into cause and effects. In addition, with recent miniaturization leading to many people with SCI owning their own stimulators, we are concerned with the implications of using them without proper monitoring facilities.

Regardless of any increases in $\mathrm{VO} 2$ and potential CVS training effects, the efficacy of any system which suppresses HR and greatly elevates BP must be seriously ques- tioned. However, it may be possible that metabolite build-up in the working muscle could 'overcome' the reflex-induced vasoconstriction of the sympathetic nervous system and decrease the hypertensive effect. This has been supported by research conducted with an FES-assisted rowing device, at the Rick Hansen Centre. ${ }^{45}$ Another possibility is the increase in opioids caused by hypertension ${ }^{46}$ somehow serving to reduce the pain of the FES and/or muscle contractions. These effects, together with the phenomenon of pain habituation may serve to explain previous unobserved occurrences.

A number of studies could be carried out to verify the dysreflexic response observed. Autonomic dysreflexia evokes a ubiquitous catecholamine response which could be measured. In addition, a study examining the HR and BP responses of paraplegics and lesion levels below T6 would be of interest. The work of Edwards and Marsolais ${ }^{24}$ with such subjects details HRs of over $150 \mathrm{bpm}$ on simultaneous FES and arm ergometry.

In summary, this system of FES-assisted hydraulic resistance training has been shown to be a potentially useful tool in the aerobic training of people with spinal cord injuries eliciting values of almost $50 \% \mathrm{VO} 2$ max during exercise. It has been shown, however, that the associated electrical stimulation is capable of producing an autonomic dysreflexia response which raises important safety concerns and calls into question the use of FES exercise for cardiovascular conditioning without careful monitoring of heart rate and blood pressure.

\section{Acknowledgements}

This research was supported in part by the Recreation Parks and Wildlife Foundation, Alberta Lotteries and The Harvey Decock Society, Edmonton Canada. Mr Ashley was supported by the Faculty of Medicine and the Rick Hansen Centre, University of Alberta, Edmonton, Canada. The authors would like to thank Andrea Wolansky and Heather Wilkins for assistance with the data collection.

\section{References}

1 Cybulski GR, Penn RD, Jaeger RS (1984) Lower extremity functional neuromuscular stimulation in cases of spinal cord injury. Neurosurgery 15: 132-146. 
2 Collins GH, West NR (1989) Prospects for axonal regrowth in spinal cord injury. Brain Res Bull 22: 89-92.

3 Nathan RH, Ohry A (1990) Upper limb functions regained in quadriplegia: a hybrid computerised neuromuscular stimulation system. Arch Phys Med Rehabil 71: 415-421.

4 Yarkony GM, Jaeger RJ, Roth E, Karlj AR, Quintern J (1990) Functional neuromuscular stimulation for standing after spinal cord injury. Arch Phys Med Rehabil 71: 201-206.

5 Andrews BJ, Baxendale RH, Barnett R, Phillips GS, Yamazaki T, Paul JP et al (1988) Hydrid FES-orthosis incorporating closed-loop control and sensory feedback. J Biomed Eng 10: 189-95.

6 Phillips CA, Petrofsky JS, Hendershot DM, Stafford D (1984) Functional electrical exercise-a comprehensive approach for physical conditioning of the spinal cord injured patient. Orthopedics 7: 1112-1123.

7 Pollack SF, Axen K, Spielholz N, Levin N, Haus F, Ragnarsson KT (1989) Aerobic training effects of electrically induced lower extremity exercises in spinal cord injured people. Arch Phys Med Rehabil 70: 214-219.

8 Ragnarsson KT (1988) Physiologic effects of FES-induced exercises in spinal cord injured individuals. Clin Orthop 233: 53-63.

9 Hooker SP, Figoni SF, Glaser RM, Rodgers MM, Ezenwa BN, Faghri PD (1990) Physiologic responses to prolonged electrically stimulated leg cycle exercise in the spinal cord injured. Arch Phys Med Rehabil 71: 863-9.

10 Nash MS, Bilsker S, Marcillo AE, Isacc SM, Botelho LA, Klose KG et al (1991) Reversal of adaptive left ventricular atrophy following electrically stimulated exercise training in human tetraplegics. Paraplegia 29: 590-99.

11 Kennedy EJ, editor (1986) Spinal Cord Injury: Facts and Figures. University of Alabama Press, Birmingham, LA.

12 Clarke KS (1966) Caloric costs of activity in paraplegic persons. Arch Phys Med Rehabil 47: 427-435.

13 Petrofsky JS, Brown SW, Cerrel-Bazo H (1992) Active physical therapy and its benefits in rehabilitation. Palaestra Spring: $23-27$ \& 61-63.

14 Mutrie N, Biddle S (1991) The Psychology of Health Related Exercise. Springer-Verlag, Hamburg.

15 Burke DC, Murray DD (1975) Handbook of Spinal Cord Medicine. Raven Press, New York.

16 Astrand PO, Rodahl K (1986) Textbook of Work Physiology. McGraw-Hill, New York.

17 American College of Sports Medicine (1991) Guidelines for Exercise Testing and Prescription. 4th ed. Lea and Febiger, Philadelphia.

18 Guyton AC (1986) Textbook of Medical Physiology. 7th ed. W B Saunders, Philadelphia.

19 Fugl-Meyer AR (1971) Effects of respiratory muscle paralysis in tetraplegic and paraplegic patients. Scand $J$ Rehabil Med 3: 141-150.

20 Eriksson P, Lofstrom L, Ekblom B (1988) Aerobic power during maximal exercise in untrained and well-trained persons with quadriplegia and paraplegia. Scand J Rehabil Med 20: 141-7.

21 Coutts KD, Rhodes EC, McKenzie DC (1983) Maximal exercise responses of tetraplegics and paraplegics. J Appl Physiol 55: 479-482.

22 Hoffman MD (1986) Cardiorespiratory fitness and training in quadriplegics and paraplegics. Sports Med 3: 312-330.

23 Riley DA, Allin EF (1973) The effects of inactivity, programmed stimulation and denervation in the histochemistry of skeletal muscle fibre types. Exp Neurol 40: 391-413.

24 Edwards BG, Marsolais EB (1990) Metabolic responses to arm ergometry and functional neuromuscular stimulation. J Rehabil Res Dev 27: 107-114.

25 Brice RM, Forster HV, Pan L, Funahashi A, Hoffman M, Lowry T et al (1986) Arterial pH and lactate during electrically induced leg exercise in paraplegics and normal subjects. Med Sci Sports Exerc 18: S91-S92.

26 Erickson RP (1980) Autonomic hyperreflexia: pathophysiology and medical management. Arch Phys Med Rehabil 61: 431-440.

27 Kurnick NB (1956) Autonomic hyperreflexia and its control in patients with spinal cord lesions. Ann Intern Med 44: 678-686.

28 Kursch ED, Freehafer A, Persky L (1977) Complications of autonomic dysreflexia. J Urol 118: 70-72.

29 Burnham R, Wheeler GD, Bhambhani Y, Belanger M, Eriksson P, Steadward RD (in press) Intentional induction of autonomic dysreflexia by quadriplegic athletes for performance enhancement: Efficacy, safety and mechanism of action. (Abstract). VISTA 1993 (May 14-20), Jasper, Alberta. Clin J Sports Med.

30 Wheeler GD, Cumming DC, Burnham R, Maclean I, Steadward RD (in press) Testosterone and catecholamine responses to exercise stress and autonomic dysreflexia in elite quadriplegic athletes. (Abstract). VISTA 1993 (May 14-20), Jasper, Alberta.

31 Moltner A, Holzl R, Strian F (1990) Heart rate changes as an autonomic component of the pain response. Pain 43: 81-89.

32 Mathias CJ, Christensen MD, Corbett JL, Frankel HL, Spalding JMK (1976) Plasma catecholamines during paroxysmal neurogenic hypertension in quadriplegic man. Circ Res 39: 204-208.

33 Arnold PB, McVey PP, Farrell WJ, Deurloo TM, Grasso AR (1992) Functional electrical stimulation: Its efficacy and safety in improving pulmonary function and musculoskeletal fitness. Arch Phys Med Rehabil 73: $665-8$. 
34 Hooker SP, Figoni SF, Rodgers MM, Glaser RM, Mathews T, Suryaprasad AG et al (1992) Metabolic and hemodynamic responses to concurrent voluntary arm crank and electrical stimulation exercise in quadriplegics. J Rehabil Res Dev 29: 1-11.

35 Figoni SF, Glaser RM, Hedershot DM, Gupter SC, Suryaprasad AG, Rodgers MM et al (1989) Hemodynamic responses of quadriplegics to maximal arm cranking and FNS leg cycling exercise. Proc 12th Ann Conf RESNA, New Orleans, Louisiana.

36 Toner MM, Glickman EL, McArdle WD (1990) Cardiovascular adjustments to exercise distributed between the upper and lower body. Med Sci Sports Exerc 22: 773-778.

37 Ragnarsson KT, O'Daniel W Jr, Edgar R, Pollack S, Petrofsky J, Nash MS (1988) Clinical evaluation of computerized functional electrical stimulation after spinal cord injury: a multicenter pilot study. Arch Phys Med Rehabil 69: 672-677.

38 Figoni SF, Glaser RM, Rodgers MM, Hooker SP, Ezenwa BN, Collins SR et al (1991) Acute hemodynamic responses of spinal cord injured individuals to functional neuromuscular stimulation-induced knee extension exercise. J Rehabil Res Dev 28: 9-18.

39 Gracanin F, Trnkoczy A (1975) Optimal stimulus parameters for minimum pain in the chronic stimulation of innervated muscle. Arch Phys Med Rehabil 56: 243-249.

40 Baker LL, Bowman BR, McNeal DR (1988) Effects of waveform on comfort during neuromuscular stimulation. Clin Orthop 233: 75-85.

41 Gruner JA, Glaser RM, Feinberg SD, Collins SR, Nussbaum NS (1983) A system for evaluation and exercise conditioning of paralyzed leg muscles. J Rehabil Res Dev 20(1): 21-30.

42 Hainaut K, Duchateau J (1992) Neuromuscular electrical stimulation and voluntary exercise. Sports Med 14(2): 100-113.

43 Matthews J, Malone L, Burnham R, Steadward RD, Wheeler GD (in press) The effects of surface anaesthetic on pain perception during functional electrical stimulation. (Abstract). VISTA 1993 (May 14-20), Jasper, Alberta.

44 Delitto A, Strube MJ, Shulman AD, Minor SD (1992) A study of discomfort with electrical stimulation. Phys Ther 72(6): 410-424.

45 Laskin JJ, Ashley EA, Olenik LM, Burnham R, Cumming DC, Steadward RD et al (1993) Electrical stimulation assisted rowing exercise with people in spinal cord injuries. A pilot study. Paraplegia 31: 534-541.

46 Sheps DS, Bragdon EE, Gray TF, Ballenger M, Usedom JE, Maixner W (1992) Am J Cardiol 70: 3F-5F. 